\section{Mitochondria: Strategic Point in the Field of Alzheimer's Disease}

\author{
Stavros J Baloyannis* \\ Department of Neurology, Aristotelian University of Thessaloniki, Greece
}

Alzheimer's disease is the most common cause of age-dependent cognitive decline composing a tragic epilogue in senility. A substantial number of cellular and biochemical mechanisms contribute in shaping the multifactorial pathogenetic background of the disease. In the neuropathological profile of Alzheimer's disease, selective neuronal loss [1], synaptic alterations [2], tau pathology [3], extracellular deposits of polymers of $\mathrm{A} \beta$ peptide [4], inflammatory responses [5] and morphological alterations of the cell organelles [6] are the most common phenomena in light and electron microscopy.

Morphological alterations of mitochondria even in the early stages of Alzheimer's disease underline the crucial role that mitochondrial structural changes and dysfunction play in the pathogenesis of Alzheimer's disease [7] and other neurodegenerative diseases, which are associated with oxidative alteration, calcium dysregulation, synaptic loss and apoptosis.

In Alzheimer's disease mitochondria may be the target for Amyloid Precursor Protein (APP) [8] and A $\beta$ peptide [9], which may induce impairment of mitochondrial dynamics [10], increasing oxidative stress [11], decreasing energy production and affecting synaptic plasticity [12]. In addition, deficits in mitochondrial function may affect APP, presenilin 1 and presenilin 2, which are closely related with the pathogenesis of Alzheimer's disease [13], aggravating the course of the disease.

The mitochondrial dysfunction may be initiated many years prior to clinical phenomenology of Alzheimer's disease [14], resulting in gradual synaptic degeneration, given that synaptic mitochondria play a crucial role in maintaining synaptic function and plasticity [15]. It is important to underline that mitochondrial alterations are associated with synaptic loss in $\mathrm{AD}$ patients, even before amyloid aggregations are detected [16]. Morphological and morphometric studies revealed that at early stages of $\mathrm{AD}$ the number of mitochondria in synaptic components is considerably decreased and their morphology changed substantially $[17,18]$.

*Corresponding author: Stavros J Baloyannis, Department of Neurology, Aristotelian University of Thessaloniki, Greece, Tel: +30 2310270434; E-mail: sibh844@otenet.gr

Citation: Baloyannis SJ (2016) Mitochondria: Strategic Point in the Field of Alzheimer's Disease. J Alzheimers Neurodegener Dis 2: 004.

Received: February 27, 2016; Accepted: March 29, 2016; Published: April 20, 2016
Recent studies revealed alterations in mitochondrial fission and fusion, due to increased $\mathrm{A} \beta$ peptide interaction with the mitochondrial protein Drp 1 [19], inducing increased mitochondrial fragmentation, impaired axonal transport of mitochondria, synaptic degeneration [20] and activation of apoptotic process, given that mitochondria fission and fusion are critical processes for mitochondrial health [21]. In addition, over expression of tau protein inhibits kinesin-dependent trafficking of mitochondria, clustering them in the perikaryon [22], decreasing the number of dendritic and synaptic mitochondria with serious consequences on synaptic plasticity [23,24], since mitochondrial transport has a high impact on synaptic homeostasis [25]. Normally mitochondrial motility and accumulation are harmoniously coordinated, since mitochondria are mainly transported to regions where the necessity for energy production and consume is particularly high, as it occurs in the synapses, which have high energy demand, for maintaining neuronal communication [26].

Therapeutic strategies targeting mitochondria may be beneficial in the initial stages of Alzheimer's disease. Thus protection to mitochondria by inhibition of mitochondrial $\beta$-oxidation [27], and therapeutic application of mitochondrial enhancers and molecules supporting the Electron Transport Chain (ETC) might play a positive role in a prodromal stage of Alzheimer's disease [28]. In experimental level modulation of mitochondrial complex I activity proved to be beneficial in multiple animal models of familial Alzheimer's disease [29]. Blockade of Cyclophilin D, which is a part of the mitochondrial permeability transition pore, may enlarge the therapeutic perspectives at the initial stage of Alzheimer's disease [30]. Controlling mitophagy may also ameliorate the clinical phenomena in some phenotypes of Alzheimer's disease [31].

In the spectrum of nanotechnology [32] mitochondria-targeting ceria nanoparticles as antioxidants may be beneficial in Alzheimer's disease [33].

In the ongoing research and the continuous endeavors to contribute therapeutically in Alzheimer's disease mitochondria remain a strategic point in the field.

\section{References}

1. Duyckaerts C, Delatour B, Potier MC (2009) Classification and basic pathology of Alzheimer disease. Acta Neuropathol 118: 5-36.

2. Baloyannis SJ, Manolidis SL, Manolidis LS (2000) Synaptic alterations in the vestibulocerebellar system in Alzheimer's disease--a Golgi and electron microscope study. Acta Otolaryngol 120: 247-250.

3. Iqbal K, Liu F, Gong CX, Grundke-lqbal I (2010) Tau in Alzheimer disease and related tauopathies. Curr Alzheimer Res 7: 656-664.

4. Gandy S (2005) The role of cerebral amyloid beta accumulation in common forms of Alzheimer disease. J Clin Invest 115: 1121-1129.

5. Hensley K (2010) Neuroinflammation in Alzheimer's disease: mechanisms, pathologic consequences, and potential for therapeutic manipulation. J Alzheimers Dis 21: 1-14.

6. Baloyannis S (2002) The Golgi apparatus of Purkinje cells in Alzheimer's disease. In: Bohl J (ed.). Neuropathology Back to the Roots, Shaker Vertag, Aachen, Germany. 
7. Swerdlow RH (2012) Mitochondria and cell bioenergetics: increasingly recognized components and a possible etiologic cause of Alzheimer's disease. Antioxid Redox Signal 16: 1434-1455.

8. Anandatheerthavarada HK, Biswas G, Robin MA, Avadhani NG (2003) Mitochondrial targeting and a novel transmembrane arrest of Alzheimer's amyloid precursor protein impairs mitochondrial function in neuronal cells. J Cell Biol 161: 41-54.

9. Pinho CM, Teixeira PF, Glaser E (2014) Mitochondrial import and degradation of amyloid- $\beta$ peptide. Biochim Biophys Acta 1837: 1069-1074.

10. Lin MT, Beal MF (2006) Alzheimer's APP mangles mitochondria. Nat Med 12: $1241-1243$.

11. Perry G, Nunomura A, Hirai K, Takeda A, Aliev G, et al. (2000) Oxidative damage in Alzheimer's disease: the metabolic dimension. Int J Dev Neurosci 18: $417-421$.

12. Harris JJ, Jolivet R, Attwell D (2012) Synaptic energy use and supply. Neuron 75: $762-777$.

13. Schon EA, Przedborski S (2011) Mitochondria: the next (neurode)generation. Neuron 70: 1033-1053

14. Yao J, Irwin RW, Zhao L, Nilsen J, Hamilton RT, et al. (2009) Mitochondria bioenergetic deficit precedes Alzheimer's pathology in female mouse model of Alzheimer's disease. Proc Natl Acad Sci U S A 106: 14670-14675.

15. Du H, Guo L, Yan SS (2012) Synaptic mitochondrial pathology in Alzheimer's disease. Antioxid Redox Signal 16: 1467-1475.

16. Reddy PH, Beal MF (2008) Amyloid beta, mitochondrial dysfunction and synaptic damage: implications for cognitive decline in aging and Alzheimer's disease. Trends Mol Med 14: 45-53.

17. Baloyannis SJ (2006) Mitochondrial alterations in Alzheimer's disease. J Alzheimers Dis 9: 119-126.

18. Baloyannis SJ (2011) Mitochondria are related to synaptic pathology in Alzheimer's disease. Int J Alzheimers Dis 2011: 305395

19. Manczak M, Calkins MJ, Reddy PH (2011) Impaired mitochondrial dynamics and abnormal interaction of amyloid beta with mitochondrial protein Drp1 in neurons from patients with Alzheimer's disease: implications for neuronal damage. Hum Mol Genet 20: 2495-2509.

20. Manczak M, Reddy PH (2012) Abnormal interaction between the mitochondrial fission protein Drp1 and hyperphosphorylated tau in Alzheimer's disease neurons: implications for mitochondrial dysfunction and neuronal damage. Hum Mol Genet 21: 2538-2547.
21. Chan DC (2012) Fusion and fission: interlinked processes critical for mitochondrial health. Annu Rev Genet 46: 265-287.

22. Ebneth A, Godemann R, Stamer K, Illenberger S, Trinczek B, et al. (1998) Overexpression of tau protein inhibits kinesin-dependent trafficking of vesicles, mitochondria, and endoplasmic reticulum: implications for Alzheimer's disease. J Cell Biol 143: 777-794.

23. Li Z, Okamoto K, Hayashi Y, Sheng M (2004) The importance of dendritic mitochondria in the morphogenesis and plasticity of spines and synapses. Cell 119: 873-887.

24. Du H, Guo L, Yan S, Sosunov AA, McKhann GM, et al. (2010) Early deficits in synaptic mitochondria in an Alzheimer's disease mouse model. Proc Natl Acad Sci U S A 107: 18670-18675.

25. Sheng ZH, Cai Q (2012) Mitochondrial transport in neurons: impact on synaptic homeostasis and neurodegeneration. Nat Rev Neurosci 13: 77-93.

26. Brown MR, Sullivan PG, Geddes JW (2006) Synaptic mitochondria are more susceptible to $\mathrm{Ca} 2+$ overload than nonsynaptic mitochondria. J Biol Chem 281: 11658-11668.

27. Chen CT, Trepanier MO, Hopperton KE, Domenichiello AF, MasoodiM, et al. (2013) Inhibiting mitochondrial $\beta$-oxidation selectivelyreduces levels of nonenzymatic oxidative polyunsaturated fatty acidmetabolites in the brain. $J$ Cereb Blood Flow Metab 34: 376-379.

28. Caldwell CC, Yao J, Brinton RD (2015) Targeting the prodromal stage of Alzheimer's disease: bioenergetic and mitochondrial opportunities. Neurotherapeutics 12: $66-80$

29. Zhang L, Zhang S, Maezawa I, Trushin S, Minhas P, et al. (2015) Modulation of mitochondrial complex I activity averts cognitive decline in multiple animal models of familial Alzheimer's Disease. EBioMedicine 2: 294-305.

30. Du H, Guo L, Fang F, Chen D, Sosunov AA, et al. (2008) Cyclophilin D deficiency attenuates mitochondrial and neuronal perturbation and ameliorates learning and memory in Alzheimer's disease. Nat Med 14: 1097-1105.

31. Martín-Maestro P, Gargini R, Perry G, Avila J, García-Escudero V (2016) PARK2 enhancement is able to compensate mitophagy alterations found in sporadic Alzheimer's disease. Hum Mol Genet 25: 792-806.

32. Marrache S, Dhar S (2012) Engineering of blended nanoparticle platform for delivery of mitochondria-acting therapeutics. Proc Natl Acad Sci U S A 109: 16288-16293.

33. Kwon HJ, Cha MY, Kim D, Kim DK, et al. (2016) Mitochondria-Targeting Ceria Nanoparticles as Antioxidants for Alzheimer's Disease. ACS Nano 10: 2860-2870. 